\title{
Early multifocal stenosis after coronary artery snaring during off-pump coronary artery bypass in a patient with diabetes
}

\author{
Roland G. Demaria, MD, ${ }^{a}, b$ Simon Fortier, MD, ${ }^{a}$ Michel Carrier, MD, and Louis P. Perrault, MD, PhD, ${ }^{a}$ \\ Montreal, Quebec, Canada, and Montpellier, France
}

$\mathrm{O}$ ff-pump coronary artery bypass surgery has gained popularity throughout the world. However, a cause for concern is that the coronary artery must be occluded to obtain a bloodless field and optimal visibility during anastomosis. Most often, sutures or tapes are used to snare the coronary artery extravascularly, upstream and downstream from the anastomotic site. We describe a case of early multifocal stenosis occurring at 3 sites of coronary artery snaring in a patient with diabetes.

\section{Clinical Summary \\ A 69-year-old woman was admitted to our institution for unstable angina. Her risk factors for cardiovascular disease included long- standing diabetes mellitus with a requirement for insulin during the past 6 years, hyperlipidemia, obesity, and arterial hyperten- sion. The right kidney and adrenal gland had been removed 7 years earlier for cancer. She was dependent on corticosteroids and had moderate renal failure. The coronary angiogram showed a tight proximal stenosis and calcifications of the right coronary artery (RCA), a stenosis of the midportion of the left anterior descending artery (LAD), and occlusion of the circumflex artery. The left ventricular ejection fraction (LVEF) was within normal limits.}

A beating-heart double coronary artery bypass procedure was performed: a left internal thoracic artery (LITA) graft was used for the LAD and a reversed saphenous vein (RSV) graft for the RCA. A bloodless surgical field was obtained by placing needle-mounted silicone rubber bands (Retract-O-Tape; Quest, Allen, Tex) snared proximally and distally near the anastomotic sites to occlude the target arteries. The anastomoses were done under optimal heart stabilization with the Cohn stabilizer (Genzyme, Fall River, Mass). Immediately after the procedure, an inferior

From the Department of Surgery and Research Center, ${ }^{\text {a }}$ Montreal Heart Institute, Montreal, Quebec, Canada, and the Cardiovascular Surgery Unit, ${ }^{\mathrm{b}}$ Arnaud de Villeneuve Teaching Hospital, Montpellier, France.

Received for publication April 5, 2001; accepted for publication April 9, 2001.

Address for reprints: Louis P. Perrault, MD, PhD, Research Center, Montreal Heart Institute, 5000 Belanger St East, Montreal, Quebec, H1T 1C8, Canada (E-mail: lpperrau@icm.umontreal.ca).

J Thorac Cardiovasc Surg 2001;122:1044-5

Copyright (C) 2001 by The American Association for Thoracic Surgery

$0022-5223 / 2001 \$ 35.00+0 \quad \mathbf{1 2 / 5 4 / 1 1 6 5 5 0}$

doi: $10.1067 / \mathrm{mtc} .2001 .116550$ myocardial infarction was noted with a new $\mathrm{Q}$ wave on the electrocardiogram and creatine kinase MB elevation to $110 \mathrm{IU} / \mathrm{L}$. Nevertheless, the patient did well and was discharged on the seventh postoperative day after an echocardiogram that showed a satisfactory LVEF (56\%).

On day 42, she was readmitted for chest pain and pulmonary edema. Echocardiography found evidence of severe left ventricular dysfunction. A repeat coronary angiogram showed that both grafts were patent but disclosed new tight stenoses upstream and downstream from the LITA-LAD anastomosis (Figure 1), a new tight stenosis upstream from the RSV-RCA anastomosis, and a $30 \%$ stenosis downstream (Figure 2). These new lesions were located at the sites of snare application. The LVEF was 35\%. The case was discussed by a multidisciplinary team, and pharmacotherapy was considered as the best option given the patient's poor general condition. Follow-up is 16 months. She has been admitted several times for left ventricular dysfunction.

\section{Comments}

Methods for obtaining a bloodless surgical field during anastomosis in beating-heart coronary artery bypass surgery include intravascular and extravascular occluders, shunts, and gas-jet insufflation. However, temporary extravascular occlusion with polypropylene sutures or silicone tapes snared on a tourniquet is used by the vast majority of surgeons. Although snaring does not cause endothelial dysfunction in healthy coronary arteries, ${ }^{1}$ abnormalities described after in vivo snaring of atheromatous coronary arteries include focal endothelial denudation, microthrombosis, and atherosclerotic plaque rupture. ${ }^{2}$ These abnormalities may promote the development of intimal hyperplasia. A direct relationship has been reported between the severity of snare-induced arterial lesions and the severity of atherosclerosis in the treated arteries. ${ }^{3}$ Furthermore, a case of atheroma embolization from a snare application site has been reported. ${ }^{4}$ The same mechanism may have caused the intraoperative infarction observed in our patient, whose arteries were calcified.

Patients with diabetes usually have severe and extensive calcification of the arterial media, with a high risk of marked intimal hyperplasia and smooth muscle proliferation in response to arterial injury. The mechanism may be cell growth stimulation and excessive extracellular matrix production caused by mitogens, such as platelet-derived growth factor and insulin-like growth factor. ${ }^{5}$ Thus, in patients with diabetes, the arterial wall injury with potential plaque rupture caused by snaring may trigger severe focal intimal hyperplasia. Sometimes, the snares had been used both to occlude the artery and to reduce arterial motion. This may have caused severe lesions at the snaring sites, thereby increasing the risk of intimal hyperplasia. In our patient, arterial motion was 


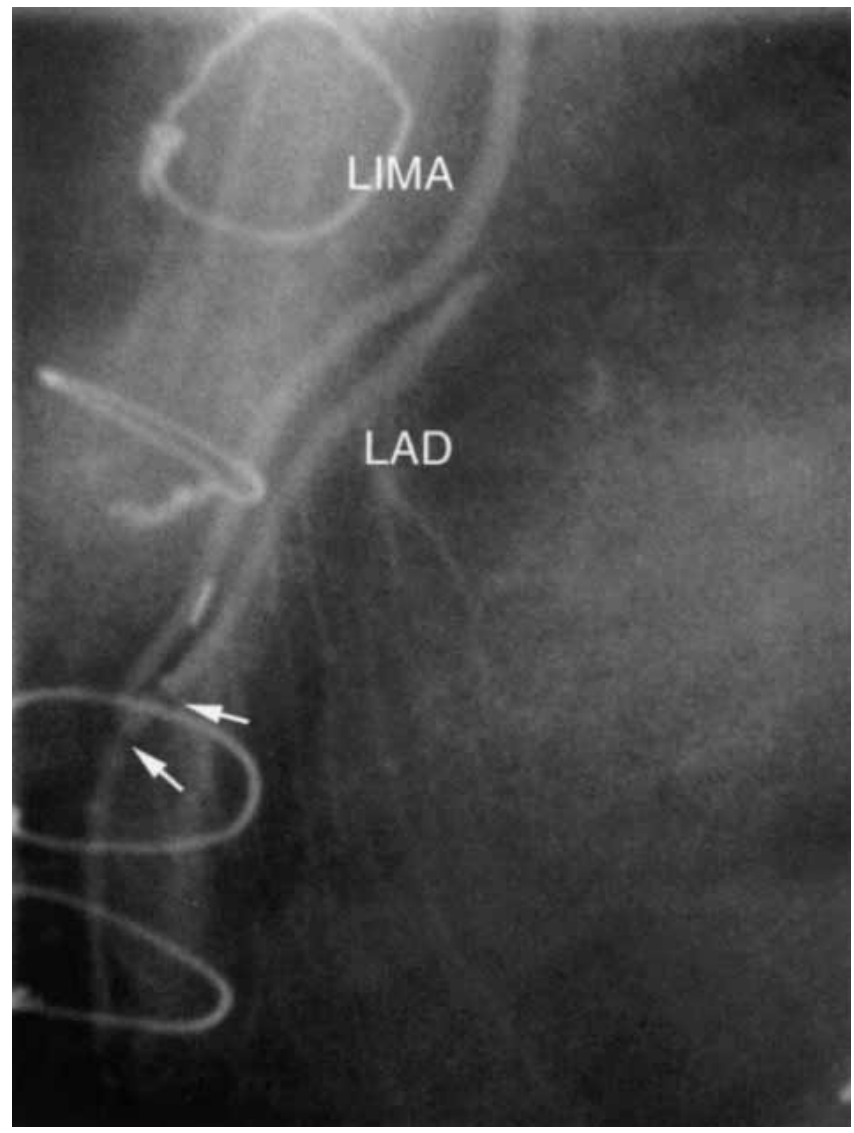

Figure 1. Postoperative coronary angiogram showing lesions upstream and downstream from the LITA-LAD anastomosis 6 weeks after off-pump surgery (arrows). The anastomosis was patent, with no stenosis.

achieved with a dedicated retractor; however, this did not prevent arterial injury at the snare site.

Occlusive snaring of calcified coronary arteries in diabetic patients during off-pump coronary artery bypass surgery should be done with caution and, if possible, only upstream from the anastomosis to eliminate the possibility of downstream stenosis, which carries a high risk of graft failure and recurrent angina. Shunting or jet-gas insufflation may be valuable alternatives in these challenging patients.

\section{References}

1. Perrault LP, Menasché P, Bidouard JP, Jacquemin C, Villeneuve N, Vilaine JP, et al. Snaring of the target vessels in less invasive bypass

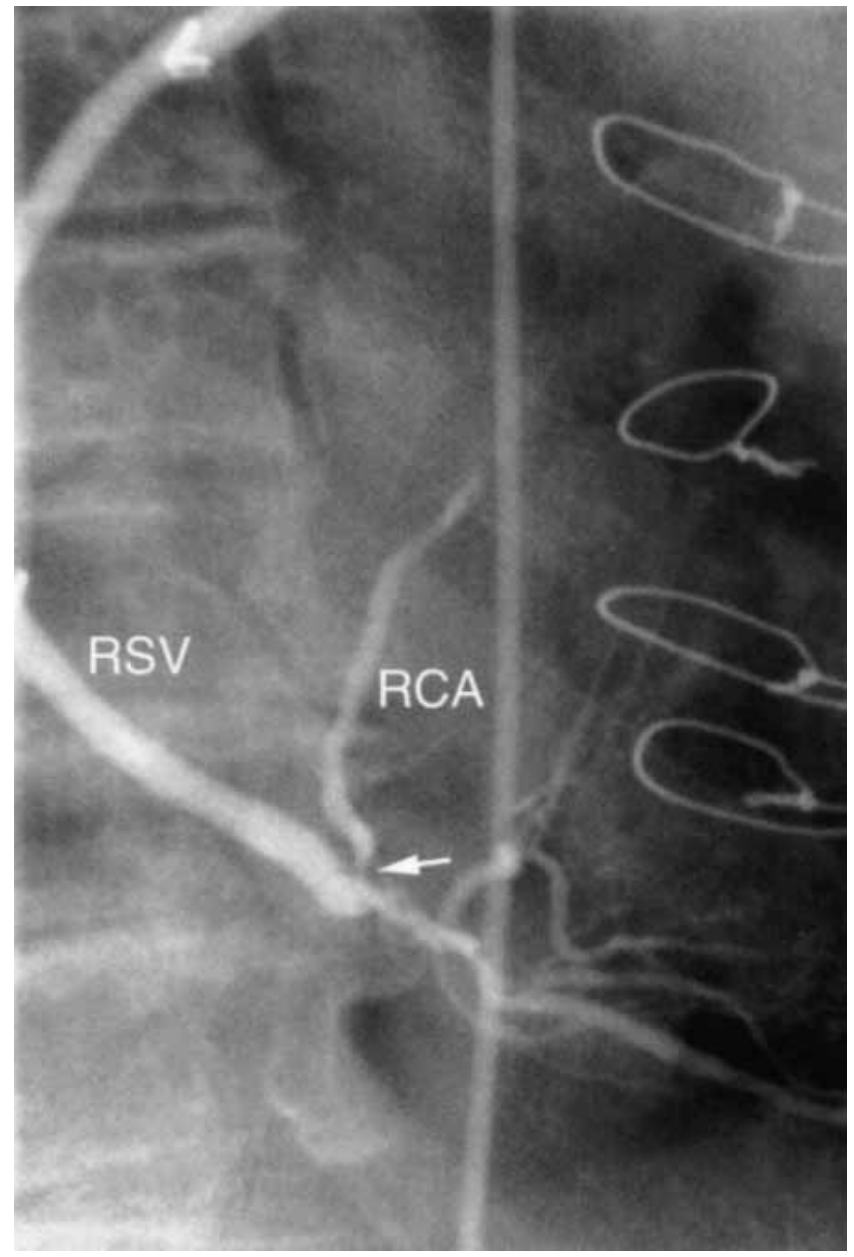

Figure 2. Postoperative coronary angiogram: New, tight stenosis upstream from the RSV-RCA anastomosis (arrow).

operations does not cause endothelial dysfunction. Ann Thorac Surg. 1997;63:751-5

2. Hangler HB, Pfaller K, Antretter H, Dapunt OE, Bonatti JO. Coronary endothelial injury after local occlusion on the human beating heart. Ann Thorac Surg. 2001;71:122-7.

3. Gerola LR, Moura LA, Leao LE, Soares HC, Branco JN, Buffolo E. Arterial wall damage caused by snaring of the coronary arteries during off-pump revascularization. Heart Surg Forum. 2000;3:103-7.

4. Izzat MB, Yim APC, El-Zufari H. Snaring of a coronary artery causing distal atheroma embolization. Ann Thorac Surg. 1998;66:1806-8.

5. Kornowski R, Mintz GS, Kent KM, Pichard AD, Satler LF, Bucher $\mathrm{TA}$, et al. Increased restenosis in diabetes mellitus after coronary interventions is due to exaggerated intimal hyperplasia: a serial intravascular ultrasound study. Circulation. 1997;95:1366-9. 